\title{
Tecnologia, sociedade e redes digitais: novas dimensões para as políticas públicas
}

Marcos Paulo Fuck

Universidade Federal do Paraná (UFPR)

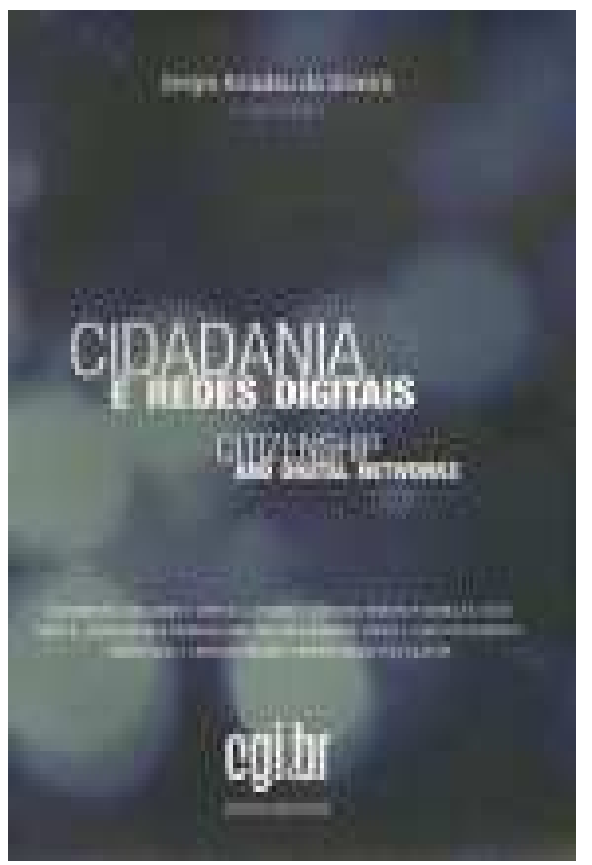

RESENHA: Tecnologia, sociedade e redes digitais: novas dimensões para as políticas públicas SILVEIRA, Sérgio Amadeu da. (Org.). Cidadania e redes digitais. 1. ed. Traduções de Daniela B. Silva, Diana Pellegrini, Flavio Augusto Paraná Pintinha e Renata Miyagusku. São Paulo: Comitê Gestor da Internet no Brasil/Maracá - Educação e Tecnologias, 2010. 247 p. Edição bilíngue.

BOOK REVIEW: Technology, Society and Digital Networks: new Dimensions for Public Policies SILVEIRA, Sérgio Amadeu da. (Org.). Citizenship and digital networks. 1. ed. Translators: Daniela B. Silva, Diana Pellegrini, Flavio Augusto Paraná Pintinha e Renata Miyagusku. São Paulo: Brazilian Internet Steering/Maracá - Educação e Tecnologias, 2010. 247 p. Bilingual edition. 
Em um contexto de profundas mudanças científicas e tecnológicas, o conhecimento é cada vez mais o fundamento da organização das atividades produtivas e, acima de tudo, da própria vida em sociedade. Não por acaso utiliza-se o termo "sociedade do conhecimento" para caracterizar a emergência de uma forma de organização social mediada por redes digitais intensivas em fluxos de informação. No livro Cidadania e redes digitais, organizado por Sergio Amadeu da Silveira, são apresentados diversos aspectos relacionados às potencialidades e aos desafios da comunicação em redes para a ampliação da cidadania, o que leva o leitor à reflexão sobre o que caracteriza a "cidadania digital", tema chave para a compreensão da sociedade contemporânea.

A obra, formada por onze textos, disponíveis em português e inglês, em versão impressa e eletrônica (http://www.cidadaniaeredesdigitais.com.br), é uma coletânea de trabalhos apresentados em seminário de mesmo título realizado em 2009, na Faculdade Cásper Líbero, em São Paulo. A opção pela interdisciplinaridade é marcante, o que possibilita ao leitor um panorama amplo das principais questões em discussão. A formação diversificada dos autores contribui para uma análise criativa das diversas nuances do conceito de "cidadania digital". O argumento principal discutido ao longo do livro é a necessidade de uma maior participação social nos debates sobre os caminhos que vêm sendo trilhados pelas novas Tecnologias de Informação e Comunicação (TICs), o que pode embasar uma ação social mais crítica e participativa em relação às novas trajetórias a serem construídas no ciberespaço.

Já no início do primeiro capítulo, escrito por Javier Bustamante, professor titular de Ética e Sociologia da Universidade Complutense de Madri, é feita uma crítica à visão mais convencional de tecnologia. Ou seja, a visão de que a tecnologia é orientada por uma lógica autônoma desvinculada do contexto social no qual se insere. Em oposição a tal visão, o autor destaca a importância de uma maior participação social em relação às decisões estratégicas relacionadas aos avanços tecnológicos. Com os avanços das TICs e das redes digitais, o autor aponta duas atitudes possíveis: o caminho até a "hipocidadania", situação de eliminação paulatina da consciência cidadã; e o caminho da "hipercidadania", que se relaciona a um exercício mais profundo da participação política, ou seja, da "cidadania digital", e que se baseia em diversos elementos, como a apropriação social da tecnologia, a promoção de políticas de inclusão digital etc.

O segundo capítulo foi escrito por Langdon Winner, professor do Departamento de Estudos de Ciência e Tecnologia na Rensselaer Polytechnic Institute em Troy, Nova York. Nele, o autor discute liberdade e cidadania a partir de dois exemplos contrastantes do mundo digital: o primeiro, um programa de computador utili- zado para encontrar evidências de plágio em trabalhos acadêmicos (o autor considera questionáveis os métodos utilizados pelo programa); o segundo, a utilização dos recursos da World Wide Web para coordenar a deliberação, a discussão, o debate e a votação de diversas questões relevantes enfrentadas pela humanidade (como o aquecimento global). Enquanto no primeiro caso, os estudantes são considerados culpados "até que o programa prove que eles são inocentes" (p. 41), no segundo, a utilização da internet pode favorecer a cidadania global, o que passa pela ampliação do commons informacional disponível às pessoas no seu cotidiano, "ampliando as oportunidades de participação direta na democracia” (p. 59). Ou seja, o autor mostra como os novos artefatos tecnológicos podem reduzir ou ampliar as liberdades individuais e a cidadania global.

Sergio Amadeu da Silveira, organizador da obra e professor da Universidade Federal do ABC, discute no terceiro capítulo questões relativas à tensão entre o fluxo de informações sem bloqueios na rede e as formas de regulamentação da internet. Em linha com os capítulos anteriores, o autor destaca a ideia de que as tecnologias são socialmente construídas, reguladas e moldadas e que, portanto, trazem embutidas em si diferentes visões de mundo, o que explica, por exemplo, os conflitos de interesses entre a indústria do copyright e as redes que utilizam diversas formas de compartilhamento de arquivos digitais, e também as polêmicas em relação aos mecanismos de controle de conexão e de navegação dos cidadãos.

O potencial de uma rede é discutido por Alexander Galloway, professor da Universidade de Nova York. $\mathrm{O}$ autor analisa diversos aspectos da Emergência da mediação no formato de rede, comentando alguns detalhes dos meios de comunicação em rede que tem ramificações na questão da cidadania digital. Carlos Afonso, diretor executivo do Instituto do Núcleo de Pesquisas, Estudos e Formação (Nupef), analisa no quinto capítulo questões referente ao trânsito na internet (o que inclui os pacotes de conexão que nos são ofertados). Afonso explica de modo acessível à forma como se dá a comercialização do acesso à internet no Brasil e constata que o preço da banda larga para os brasileiros é um dos mais caros do mundo, a qualidade é baixa e a oferta é restrita a poucos municípios.

Mesmo considerando que o acesso à internet não é realidade em todo o território nacional, sua utilização para disponibilizar dados governamentais pode representar avanços para a transparência das ações por parte da esfera pública. Daniela Silva, facilitadora da Peer 2 Peer University, destaca que o conceito de dados governamentais abertos (Open Government Data) se refere não só à disponibilização de informações por parte do governo, mas que esse processo pode permitir que "a inteligência coletiva crie me- 
lhores formas de trabalhá-las do que os próprios governos poderiam fazer" (p. 121). Isto reafirma o potencial das TICs e da rede para a ampliação da participação social no processo de decisões políticas.

Giuseppe Cocco, professor titular da Universidade Federal do Rio de Janeiro, discute no sétimo capítulo a comunicação e os direitos humanos frente às profundas transformações do capitalismo contemporâneo, destacando, entre outros aspectos, a necessidade da democratização da mídia e a ampliação dos direitos do comum (como no caso do movimento do copyleft e do software livre). No oitavo capítulo, Fabio Josgrilberg, professor da Universidade Metodista de São Paulo, defende que há que se fazer uma opção radical pela comunicação na cidade, intensificando os fluxos comunicacionais formais e informais de modo a ampliar a percepção crítica da realidade local, garantindo "o mínimo de veracidade para a ação individual e coletiva no mundo" (p. 161). Isso implica em se pensar além dos fóruns formais de participação política e dos conteúdos tradicionais das mídias, destacando a relevância de fluxos comunicacionais livres e universais.

Dando sequência às discussões apontadas acima, no capítulo nove, Franklin Coelho, professor do Departamento de Economia da Universidade Federal Fluminense, destaca a importância do acesso à informação como um direito fundamental e que deve estruturar as políticas públicas que visem o acesso da população à sociedade do conhecimento. A implantação de redes de transmissão de dados, voz e imagem é algo que dá base a estas ações. Segundo o autor, "as cidades adquirem um novo conteúdo a partir dos novos fluxos que se entrelaçam com o virtual estruturando redes sociais concretas, repensando a relação entre essas novas tecnologias e o território" (p. 197). Neste processo, observa-se a interação entre o espaço herdado, a cidade industrial, e o espaço projeto, a cidade informacional, sendo a reestruturação do território mediada pelo jogo de forças sociais. A cidade digital, ambiente no qual o chamado ciberespaço se transforma e se reterritorializa, "abre a possibilidade de uma incorporação social da tecnologia ao permitir uma estratégia de inclusão digital e de garantia do acesso à informação e a gestão do conhecimento" (p. 199).

No décimo capítulo, Carolina Rossini, coordenadora do projeto Recursos educacionais abertos: desafios e perspectivas, apresenta as principais características do acesso aberto, que se refere à ausência de barreiras financeiras, legais e técnicas ao acesso à literatura científica na internet, e dos Recursos Educacionais Abertos, que estimulam a produção colaborativa, a partilha do conteúdo, a troca de metodologias etc. Estas duas visões, na avaliação da autora, são "formadoras de políticas públicas apropriadas à democracia na sociedade do conhecimento" (p. 229). O último capítulo do livro foi escrito por Jomar Silva, diretor-geral da ODF Aliance América Latina. Nele, o autor explica as principais características do padrão Open Document Format (ODF) e defende a importância deste formato aberto para a livre circulação e perenidade da informação.

Como visto, um aspecto chave tratado ao longo da obra é a apropriação social da tecnologia. Isto é, a utilização da tecnologia de modo mais articulado às demandas sociais, indo além das questões mais diretamente relacionadas à lógica competitiva dos mercados nos quais ela se insere. Dada a imensa diversidade cultural, política e econômica que caracteriza nossa sociedade, trata-se de um processo bastante complexo e que, para se ampliar as chances de sucesso dessa estratégia, deve estar articulado a políticas públicas criativas que ampliem a participação da sociedade nas definições que envolvem as diversas formas de difusão do conhecimento. Em meio a isto, deve-se destacar a necessidade de uma discussão mais profunda sobre os próprios mecanismos de propriedade intelectual, em especial os relacionados à proteção de ativos na indústria de software, ou seja, às formas de apropriação privada utilizadas neste segmento, algo que poderia ter sido objeto de um capítulo específico de modo a possibilitar que o leitor leigo tenha um melhor entendimento do debate.

Além de bastante agradável, a leitura do livro permite reflexões sobre a dinâmica das relações que se estabelecem entre as TICs, as redes digitais e as novas dimensões da cidadania. Em um momento em que se discutem as novas formas de regulação da internet no Brasil, a ampliação do acesso da população às redes digitais, uma maior transparência das ações por parte do poder público, a ampliação das práticas colaborativas em atividades acadêmicas e culturais, entre outros aspectos, a obra se apresenta como referência importante para balizar os debates sobre as novas dimensões das relações entre tecnologia e sociedade.

\section{Marcos Paulo Fuck}

marcospaulofk@ufpr.br

Doutor em Política Científica e Tecnológica pela Unicamp

Professor adjunto do Departamento de Economia e do Programa de Pós-Graduação em Políticas Públicas da Universidade Federal do Paraná (UFPR)

\section{UFPR}

Av. Prefeito Lothário Meissner, 632, térreo, sala 01 Jardim Botânico

Curitiba - Paraná

CEP: $80210-170$ 